\title{
A REVIEW ON POWER ELECTRONICS APPLICATION ON WIND TURBINES
}

\author{
Yogesh Murthy.N \\ Lecturer, Dept of Electrical and Electronics Engineering, SIET (shridevi institute of Engineering and Technology), \\ Tumkur, Karnataka.yogeshmurthy260@gmail.com
}

\begin{abstract}
This paper reviews the power electronic applications for wind energy systems. Various wind turbine systems with different generators and power electronic converters are described, and different technical features are compared. The electrical topologies of wind farms with different wind turbines are summarized and the possible uses of power electronic converters with wind farms are shown. Finally, the possible methods of using the power electronic technology for improving wind turbine performance in power systems to meet the main grid connection requirements are discussed.
\end{abstract}

Keywords_Fault ride-through, grid connection, power electronics converters, reactive power compensation, wind energy conversion, wind farms, wind turbine control.

\section{INTRODUCTION}

OVER the last ten years, the global wind energy capacity has increased rapidly and became the fastest developing renewable energy technology. By the end of 2006, the global wind electricity-generating capacity has increased to $74223 \mathrm{MW}$ from $59091 \mathrm{MW}$ in 2005. The early technology used in wind turbines was based on squirrel-cage induction generators (SCIGs) directly connected to the grid. Recently, the technology has developed toward variable speed. The controllability of the wind turbines becomes more and more important as the power level of the turbines increases.

Power electronic, being the technology of efficiently converting electric power, plays an important role in wind power systems. It is an essential part for integrating the variable-speed wind power generation units to achieve high efficiency and high performance in power systems. Even in a fixed-speed wind turbine system where wind power generators are directly connected to the grid, thyristors are used as softstarters. The power electronic converters are used to match the characteristics of wind turbines with the requirements of grid connections, including frequency, voltage, control of active and reactive power, harmonics, etc.

This paper reviews the major applications of power electronics for wind power conversion systems, and it is organized as follows. Section II shows a brief review of the wind energy conversion systems and modern power electronics. Then, applications of power electronics for wind turbines are presented.
Section III discusses the issues of operating wind turbines in power systems, and Section IV presents the power quality issues and dynamic performances. Finally, in Section V, the conclusions are drawn and the future trends are illustrated.

\subsection{Introduction of Wind Energy Conversion Systems}

Thermal in components of a wind turbine system are illustrated in Fig. 1, including a turbine rotor, a gearbox, a generator, a power electronic system, and a transformer for grid connection. Wind turbines capture the power from wind by means of turbine blades and convert it to mechanical power. It is important to be able to control and limit the converted mechanical power during higher wind speeds. The power limitation may be done either by stall control, active stall, or pitch control whose power curves are shown in Fig. 2 [1], [2]. It can be seen that the power may be smoothly limited by rotating the blades either by pitch or active stall control while the power from a stall-controlled turbine shows a small overshoot and a lower power output for higher wind speed. The common way to convert the low-speed, high-torque mechanical power to electrical power is using a gearbox and a generator with standard speed. The gearbox adapts the low speed of the turbine rotor to the high speed of the generator, though the gearbox may not be necessary for multipole generator systems.

The generator converts the mechanical power into electrical power, which being fed into a grid possibly through power electronic converters, and a transformer with circuit breakers and electricity meters. The two most common types of 
electrical machines used in wind turbines are induction generators and synchronous generators.

Induction generators with cage rotor can be used in the fixed speed wind turbines due to the damping effect. The reactive power necessary to energize the magnetic circuits must be supplied from the network or parallel capacitor banks at the machine terminal that may have the danger of self-excitation, when connection to the network is lost. In such a case, the terminal voltage or reactive power may not be directly controlled, and the induction generators may suffer from voltage instability problem, which is becoming a significant concern with large-scale wind farm penetration. A wound rotor induction machine has a rotor with copper windings, which can be connected to an external resistor or to ac systems via power electronic systems. Such a system provides a partial variable-speed operation with a small power Electronic converter, and therefore increased energy capture and reduced mechanical load to the system. This type of system is an economical way to supply reactive power and obtain variable speed for increased energy yield at wind speeds below the rated speed. Synchronous generators are excited by an externally applied dc or by permanent magnets (PMs). There is considerable interest in the application of the multiple-pole synchronous generators (either with PM excitation or with an electromagnet) driven by a wind-turbine rotor without a gearbox or with a low ratio gearbox. Synchronous machines powered by wind turbines may not be directly connected to the ac grid because of the requirement for significant damping in the drive train. The use of a synchronous generator leads to the requirement for a full rated power electronic conversion system to decouple the generator from the network. While most of the turbines are nowadays connected to the mediumvoltage system, large offshore wind farms may be connected to the high-voltage and extra high-voltage systems. The transformer is normally located close to the wind turbines to avoid high current flowing in long low-voltage cables. The electrical protection system of a wind turbine system protects the wind turbine as well as secures the safe operation of the network.

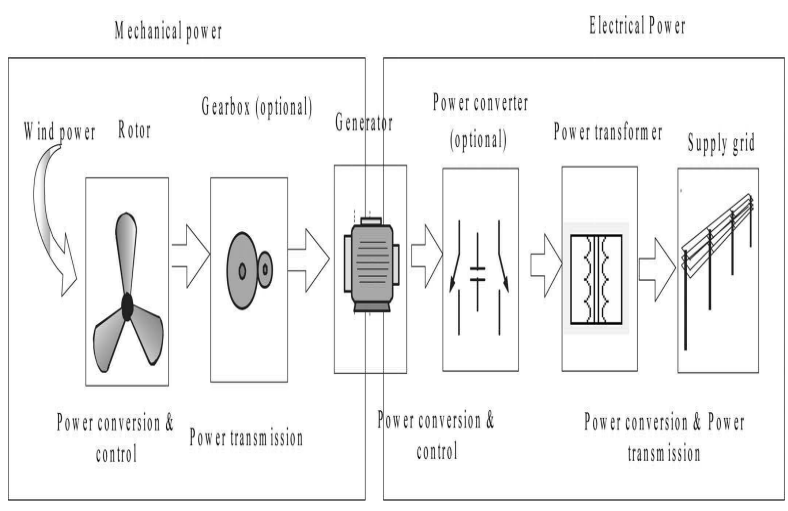

Fig. 1. Main components of a wind turbine system.

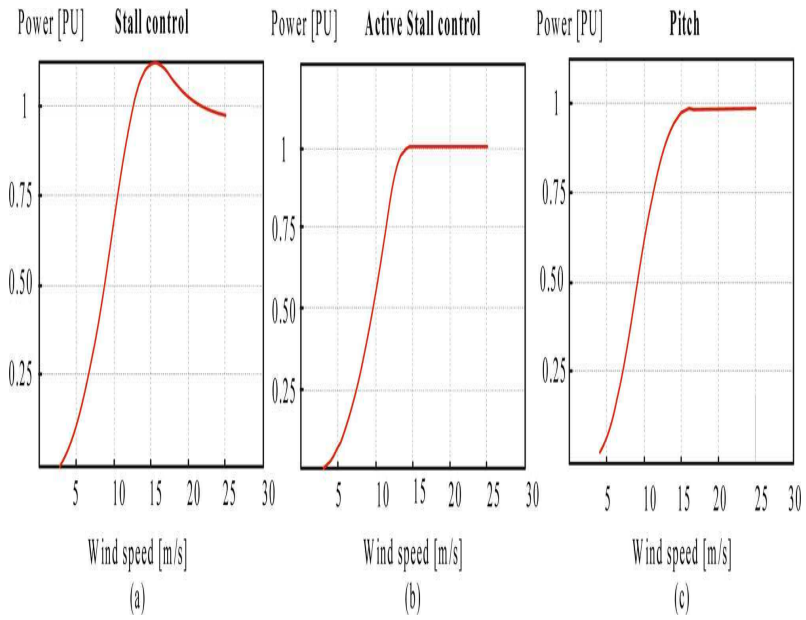

Fig. 2. Power characteristics of fixed-speed wind turbines [2]. (a) Stall control. (b) Active stall control. (c) Pitch control.

\subsection{Modern Power Electronics}

Power electronics has changed rapidly during the last 30 years and the number of applications has been increasing, mainly due to the developments of the semiconductor devices and the microprocessor technology. For both cases, the performance is steadily increasing, and at the same time, the price of devices is continuously falling. In order to improve reliability and reduce cost, the number of components is going down by a higher level of integration. The power electronic device technology is still undergoing important progress, including some key self-commutated devices, such as insulated gate bipolar transistor (IGBT), MOSFET, integrated gate commutated thyristors (IGCT), MOS-gate thyristors, and silicon carbide FETs. The breakdown voltage and/or current carrying capability of the components are also continuously increasing. Important research is going on to change the material from silicon to silicon carbide. This may dramatically increase the power density of the power converters. Power electronic converters are constructed by semiconductor devices, driving, protection, and control circuits to perform voltage magnitude and frequency conversion and control. A converter, depending on the topology and application, may allow both directions of power flow. There are two different types of converter systems: grid commutated and selfcommutated converter systems. The grid commutated converters are mainly thyristors converters with high power capacity of 6 or 12 or even more pulses. A thyristors converter consumes inductive reactive power and it is not able to control the reactive power. Thyristors converters are mainly used for very high voltage and power applications, such as conventional HVDC systems. Self-commutated converter systems normally adopt pulse width- modulated (PWM) control methods; the semiconductors with turn-OFF ability, such as IGBTs, are mainly used. This type of converter may transfer both active power and reactive power [3], [4] in both 
directions (ac-dc or $\mathrm{dc}-\mathrm{ac}$ ). This means that the reactive power demand can be delivered by a PWM converter. The high-frequency switching of a PWM converter may produce harmonics and inter harmonics, which, in general, are in the range of some kilohertz. Due to the high frequencies, the harmonics are relatively easier to be removed by Small-size filters. Fig. 3 shows a typical power electronic converter consisting of self-commutated semiconductors such as IGBTs. Other types of circuit configurations also exist, including the multilevel converters, as shown in Fig. 4, and the matrix converter, as shown in Fig. 5. Especially, the multilevel converters are very interesting in such applications due to the voltage level of the converters and the decrease of the harmonics, and consequently, the size of the output filters. The matrix converter is technically more complicated.

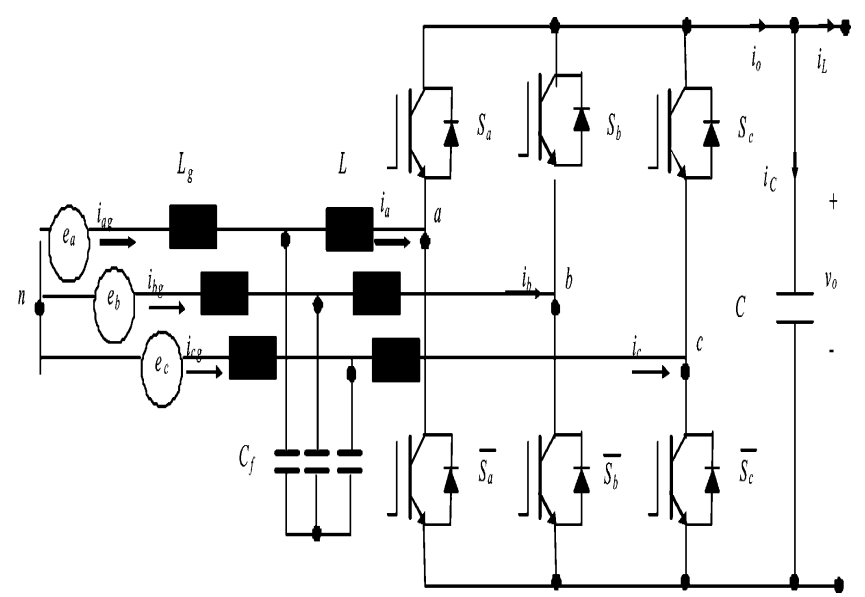

Fig. 3. Circuit diagram of a VSC with IGBTs.

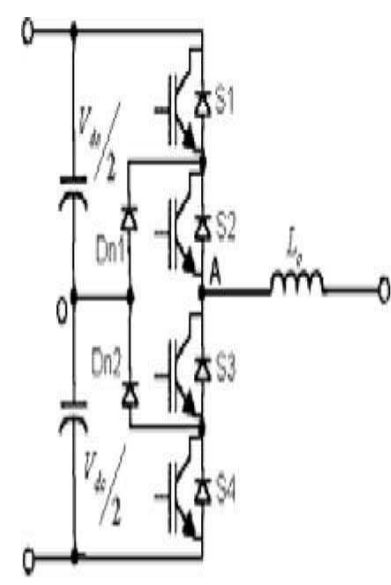

(a)

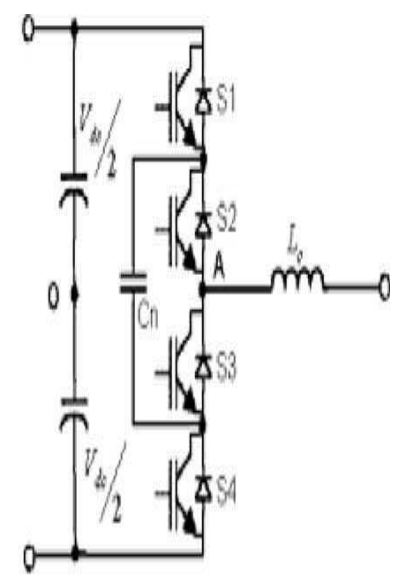

(b)
Fig. 4. Three-level VSCs. (a) Three-level neutral point clamped VSC. (b) Three-level flying capacitor VSC.

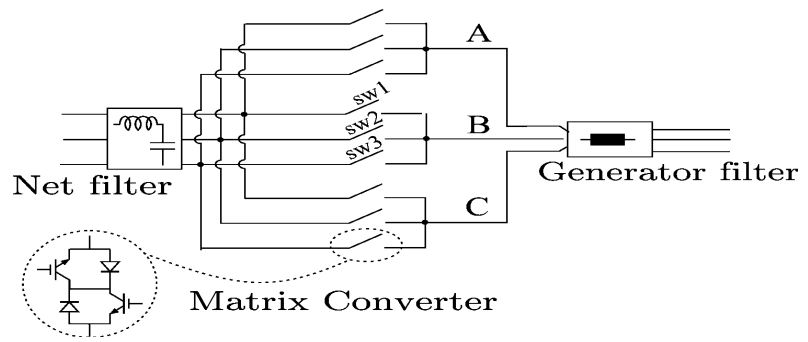

Fig. 5. Circuit configuration of a matrix converter.

\section{POWER ELECTRONICS FOR INTEGRATION AND CONTROL OF WIND TURBINES}

Many possible technical solutions of wind turbine electrical systems are related to power electronics, since they can improve dynamic and steady-state performances, help to control the wind turbine generator, and decouple the generator from the electrical grid [2], [4]. Some major power electronic applications are described in this section.

\subsection{Soft-Starter for Fixed-Speed Wind Turbines}

The "Danish concept" [1] of directly connecting a wind turbine to the grid is widely used in early wind turbine systems. The scheme consists of an SCIG, connected via a transformer to the grid and operating at an almost fixed speed. The power can be limited aerodynamically either by stall control, active stall, or pitch control.

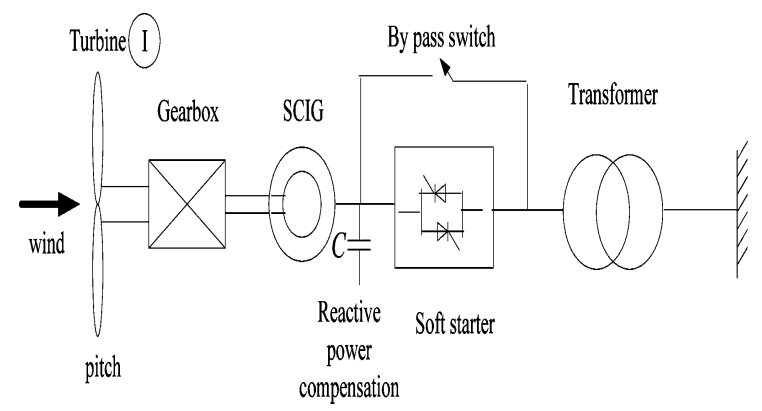

Fig. 6. Cage-induction-generator-based fixed-speed wind turbine with power electronic soft-starter.

The basic configurations of the fixed-speed concepts are shown in Fig. 6. The advantages of wind turbines with induction generators are the simple and cheap construction, in addition that no synchronization device is required. These solutions are attractive due to cost and reliability. Some drawbacks are: 1) the wind turbine has to operate at constant speed; 2) it requires a stiff power grid to enable stable operation; and 3) it may require a more expensive mechanical construction in order to absorb high mechanical stress, since wind gusts may cause torque pulsations on the drive train. Connecting the induction generators to power system produces 
transients that are short duration with very high inrush currents, thus causing disturbances to both the grid and high torque spikes in the drive train of wind turbines with a directly connected induction generator. Such a transient disturbs the grid and limits the acceptable number of wind turbines. The high starting currents of induction generators are usually limited by a thyristors soft-starter. The current limiter or softstarter, based on thyristors technology, typically limits the rms value of the inrush current to a level below two times of the generator rated current. The soft-starter has a limited thermal capacity and it is short circuited by a contactor, which carries the full-load current, when the connection to the grid has been completed. In addition to reduce the impact on the grid, the soft-starter also effectively dampens the torque peaks associated with the peak currents, and hence reduces the loads on the gearbox.

\subsection{Power Electronics for Variable-Speed Wind}

\section{Turbines}

Variable-speed operation of a wind turbine system has many advantages. For instance, the wind turbine can increase or decrease its speed if the wind speed and torque vary. This means less wear and tear on the tower, gearbox, and other components in the drive train. Also, variable-speed systems can increase the production of the energy and reduce the fluctuation of the power injected into the grid. In variablespeed systems, the generator is normally connected to the grid through a power electronic system.

For synchronous generators and induction generators without rotor windings, a full rated power electronic system is connected between the stator of the generator and the grid, where the total power production must be fed through the power electronic system [5], [6]. For induction generators with rotor windings, the stator of the generator is connected to the grid directly, and the rotor is connected to a power-electroniccontrolled resistor or connected to the network through slip rings and a power electronic converter.

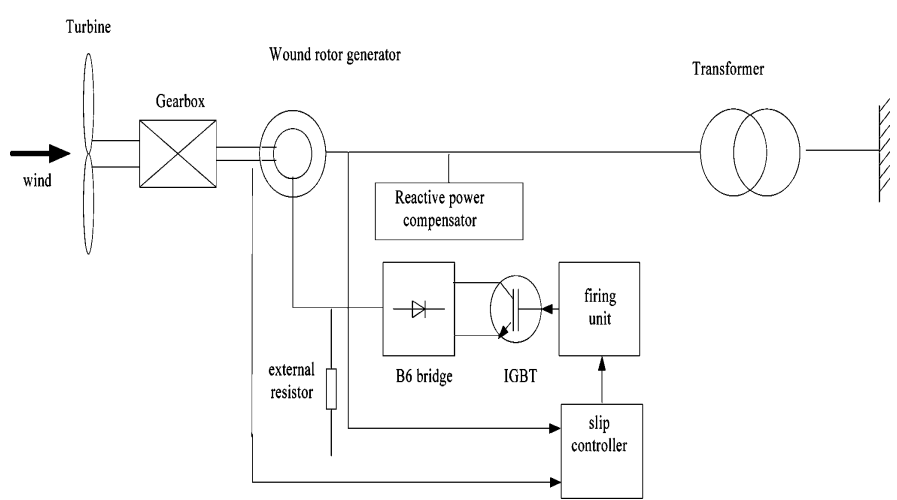

Fig. 7. Wound rotor induction generator with a rotor resistance converter [9].

\subsubsection{Wounded Rotor Induction Generator With}

\section{Rotor Resistance Control (Dynamic Slip Control):}

In this scheme, the rotor windings are connected with variable resistors. The equivalent resistance in the circuit can be adjusted by an electronic control system, as shown in Fig. 7. The higher the resistance of the rotor windings, the higher the slip is. In this way, the generator speed can be varied in a limited range. Conventionally, the connection is usually done with brushes and slip rings, which is a drawback in comparison with the simple technical design of a cage rotor induction machine. It also introduces parts, which raise the maintenance requirements. This solution still needs a softstarter [7], [8]. Both cage induction generators and rotor resistance- controlled wounded induction generators need to operate at a super synchronous speed to generate electricity. Both of them draw reactive power that might be supplied from the grid or from installed compensation equipment, such as capacitor banks or additional power electronic equipment. In order to keep the cost as low as possible, capacitor banks are normally used. Modern megawatt-class turbines have thyristors switched capacitors (TSCs) allowing for a more dynamic compensation.

A static Var compensator (SVC) or similar technology may be needed to improve the dynamic responses of the wind farm, as will be shown in Section III.

\subsubsection{Doubly Fed Induction Generator:}

The stator of a doubly fed induction generator (DFIG) is connected to the grid directly, while the rotor of the generator is connected to the grid by electronic converters through slip rings, as shown in Fig. 8. The generator can deliver energy to the grid at both super synchronous and sub synchronous speeds. The slip is varied with the power flowing through the power electronic circuit. The advantage is that only a part of the power production is fed through the power electronic converter. Hence, the nominal power of the power electronic converter system can be less than the nominal power of the wind turbine. In general, the nominal power of the converter may be about $30 \%$ of the wind turbine power, enabling a rotor speed variation in the range of about $30 \%$ of the nominal speed. By controlling the active power of the converter, it is possible to vary the rotational speed of the generator, and thus the speed of the rotor of the wind turbine. Self-commutated converter systems, such as IGBT-based switching converters, are normally used for this type of system. As shown in Fig. 8, the DFIG normally uses a back-to-back converter, which consists of two bidirectional converters sharing a common dc link, one connected to the rotor and the other one to the grid. The power electronic converters for variable-speed generators have the ability to control both the active and reactive power delivered to the grid. This gives potential for optimizing the grid integration with respect to steady-state operation 
conditions, power quality, voltage, and angular stability. The reactive power to the grid from the generation unit can be controlled as zero or to a value required by the system operator within the converter rating limit. In general, the harmonics generated by the converter are in the range of some kilohertz. Thus, filters are necessary to reduce the harmonics. The DFIG system also enables the application of special operation strategies and provides the high-quality power to the grid. The acoustical noise from the wind turbines can effectively be reduced since the system can operate at a lower speed when the wind becomes quiet. The dynamic response and controllability are excellent in comparison with traditional induction generator Systems. The DFIG solution needs neither a soft-starter nor a reactive power compensator.

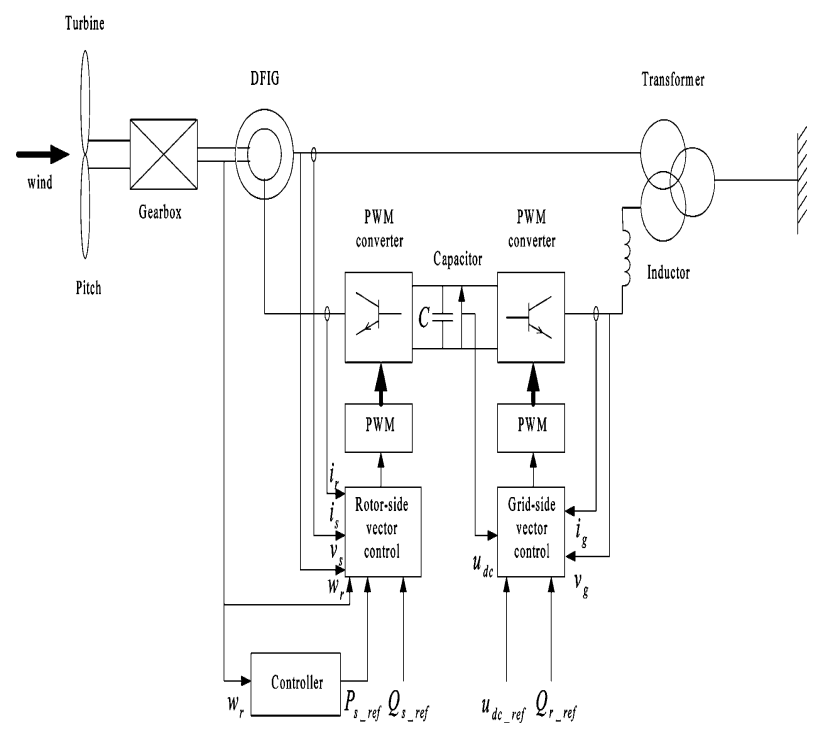

Fig. 8. Wind turbine topologies with DFIG

The control system of a variable-speed wind turbine with DFIG mainly functions to:

1) Adjust the power drawn from the wind turbine in order to track the optimum operation point;

2) limit the power in the case of high wind speeds;

3) Regulate the reactive power exchanged between the wind turbine and the grid.

An example of an overall control scheme of a wind turbine with a doubly fed generator system is shown in Fig. 9: there are two related hierarchical control levels with different bandwidths, namely DFIG control level and wind turbine control level.

The DFIG control level performs the control of the rotor side and the grid-side back-to-back converters. A vector control approach is adopted for the rotor controller, while two cross coupled controllers adjust the speed and power of the system. The goals of such controllers are to track the optimum operation point, limit the power in the case of high wind speeds, and control the reactive power exchanged between the wind turbine generator and the grid. The control of the gridside converter keeps a constant dc-link voltage while injecting the active power to the grid. Internal current loops in both converters are typically using proportional-integral (PI) controllers. Most wind turbines use the pitch angle of the blades to limit the power when the turbine reaches the nominal power. Below the maximum power production, the wind turbine will vary the speed proportional to the wind speed and keep the pitch angle nearly fixed. At a very low wind, the speed of the turbine will be fixed at the maximum allowable slip to avoid overvoltage. The wind turbine control, with slow dynamic response, supervises both the pitch system of the wind turbine as well as the active power set point of the DFIG control level. Also, some modulation methods have been proposed to improve the performance, such as in [47].

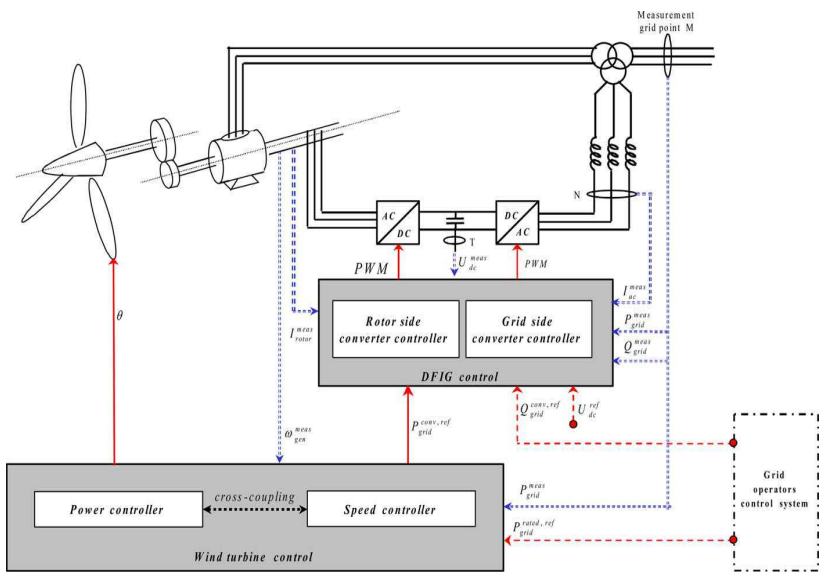

Fig. 9. Control of wind turbine with the DFIG system [10].

\subsubsection{Wind Turbine Systems With Full Rated Power}

\section{Electronic Converters:}

Cage induction generators and synchronous generators may be integrated into power systems with full rated power electronic converters. The wind turbines with a full scale power converter between the generator and grid give the added technical performance. Usually, a back-to-back voltage source converter (VSC) is used in order to achieve full control of the active and reactive power, though with synchronous generators, diode rectifiers may be used [3], [4], [1], [2], but in this case, it would be more difficult to fully control the whole system. Since the generator is decoupled from the grid in this system, the generator can operate at a wide variable frequency range for optimal operation while the generated active power will be sent to the grid through the grid-side converter that can be used for controlling the active and reactive power independently [3], [4], and the dynamic response may be improved. Fig. 10 shows four possible solutions with full- 
scale power converters. All four solutions have almost the same controllable characteristics since the generator is decoupled from the grid by a dc link. The grid-side converter enables the system to control active and reactive power very fast. However, the negative side is a more complex system with more sensitive electronic parts. The configurations shown in Fig. 10(a) and (b) are characterized by having a gearbox. The wind turbine system with a cage rotor induction generator and full rated power electronic converters is shown in Fig. 10(a). The synchronous generator has shown in Fig. 10(b) needs a small power converter for field excitation. Multipole systems with the synchronous generator without a gear are shown in Fig. 10(c) and (d). The last solution uses PMs, which are becoming cheaper and thereby attractive.

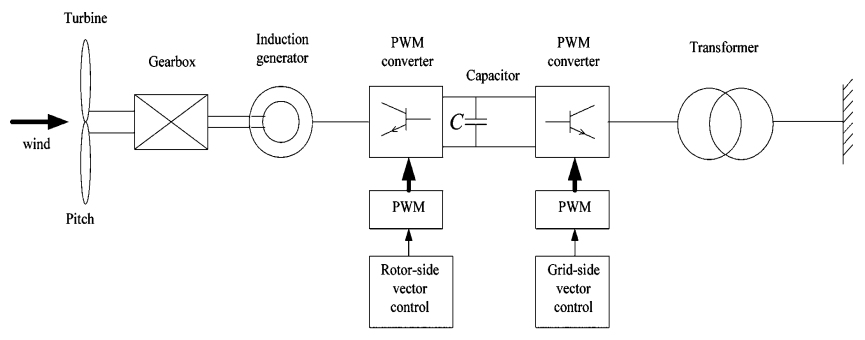

(a)

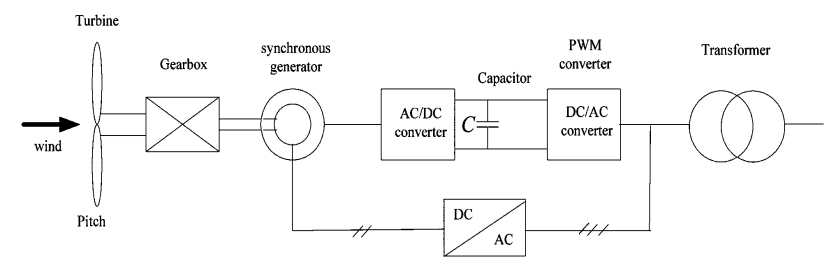

(b)

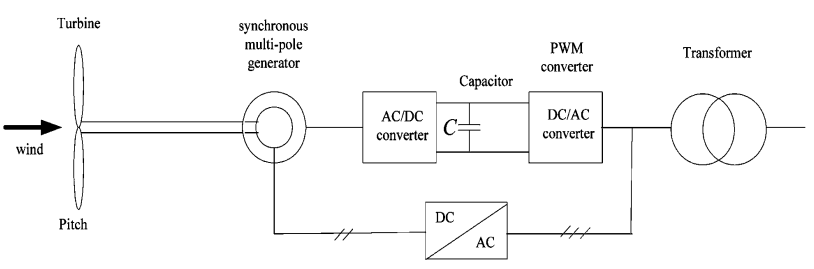

(c)

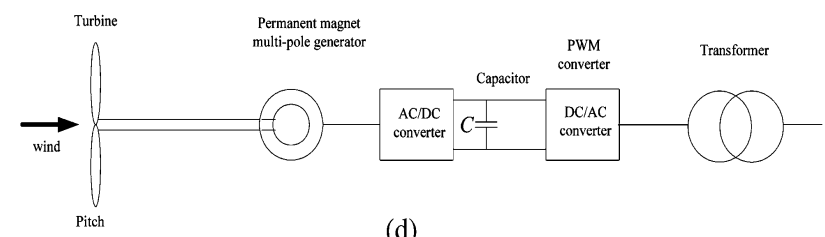

Fig. 10. Wind turbine systems with full-scale power converters. (a) Induction generator with gear. (b) Synchronous generator with gear. (c) Multipole synchronous generator. (d) Multipole PM synchronous generator

\subsubsection{Maximum Wind Power Control}

As discussed previously, variable-speed wind turbines are able to operate at an optimal rotation speed as a function of the wind speed. The power electronic converter may control the turbine rotation speed to get the maximum possible power by means of a maximum power point tracking (MPPT) algorithm. In this way, it is also possible to avoid exceeding the nominal power if the wind speed increases. At the same time, the dclink capacitor voltage is kept as constant as possible, achieving a decoupling between the turbine-side converter and the grid-side converter. The grid-connected converter will work as an inverter, generating a PWM voltage whose fundamental component has the grid frequency, and also being able to supply the active nominal power to the grid. The power generated by a wind turbine can be expressed as

$$
P=1 / 2 \rho \pi R 2 V 3 C p
$$

Where $\rho$ is the air density (in kilograms per cubic meter), $R$ is the turbine rotor radius, $V$ is the wind speed, and $C P$ is the turbine power coefficient that represents the power conversion efficiency of a wind turbine. $C P$ is a function of the tip speed ratio (TSR), $\lambda$, as well as the blade pitch angle $(\beta)$ in a pitch controlled wind turbine. $\lambda$ is given by

$$
\lambda=R v / V
$$

Where $v$ is the rotational speed of the wind turbine. The Betz limit, $C P, \max ($ theoretical $)=16 / 27$, is the maximum theoretically possible turbine power coefficient. In practice, it is $40 \%-45 \%$ [13]. The rotor efficiency curve $C p(\lambda)$ is a nonlinear function of the TSR, $\lambda$, which is determined by the blade design, and the pitch angle. From Fig. 11(a), it is clear that there is a value of $\lambda$ for which $C p$ is maximized, thus maximizing the power for a given wind speed. Because of the relationship between $C p$ and $\lambda$, for each wind velocity, there is a turbine speed that gives a maximum output power. The peak power points for various wind speeds are shown in Fig. 11(b) [4]. Normally, a variable-speed wind turbine follows the $C P$, max to capture the maximum power up to the rated speed by varying the rotor speed to keep the system at the optimum TSR, iopt .

An example of the relationship between the wind speed and the power generated by the wind turbine is shown in Fig. 12. The blades start to move around $4 \mathrm{~m} / \mathrm{s}$, and optimal aerodynamic efficiency is achieved up to the rated wind speed, about $15 \mathrm{~m} / \mathrm{s}$.

Between the rated wind speed and $25 \mathrm{~m} / \mathrm{s}$, the power delivered is limited in order to avoid overloading on the wind turbine system. Over the cutout wind speed, the turbine has to be stopped in order to avoid damages. During the optimal efficiency wind speed range, the wind generator may be adjusted to follow the maximum power point. 
There are some methods to perform MPPT control for wind turbines [4].

1) TSR Control: Fig. 13 shows this kind of MPPT controller, which needs the wind speed measured by an anemometer. The controller regulates the wind turbine speed to maintain an optimal TSR [5]. However, the accurate wind speed may be difficult to obtain. In addition, the use of an external anemometer increases the complexity and cost of the system.

2) Power Signal Feedback (PSF) Control: This control, depicted in Fig. 14, requires the knowledge of the maximum power curves of the turbine, which may be obtained through simulations and practical tests [16]. The speed of the wind turbine is used to select the stored power curve, which gives the target power to be tracked by the system. In many cases, this power curve may be substituted by a predictor or an observer of the wind speed as a function of the power and the wind-turbine speed.

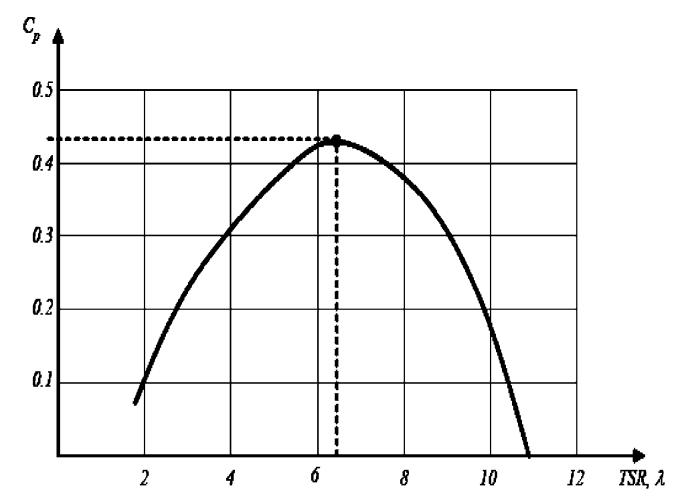

(a)

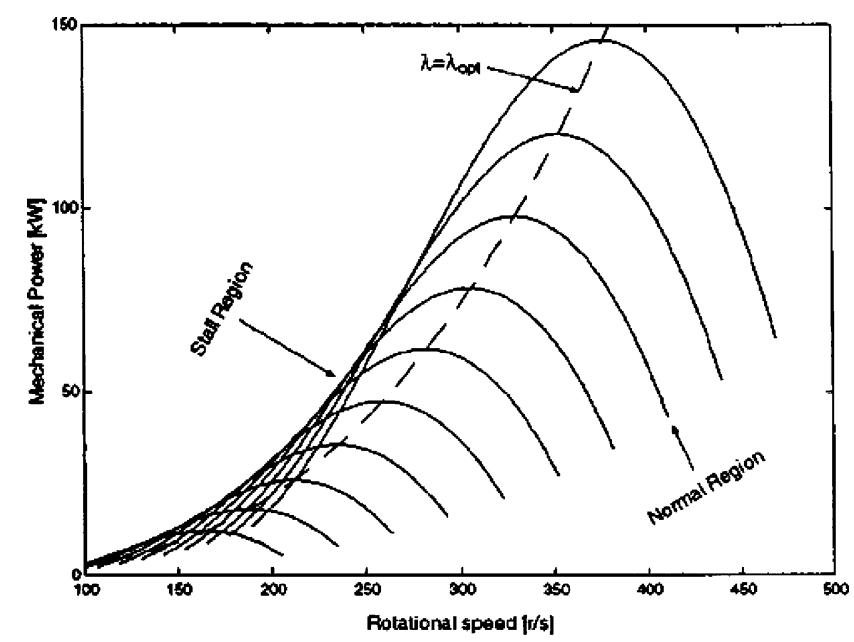

(b)

Fig. 11. (a) Relationship between the TSR and the power coefficient (with a fixed pitch angle). (b) Maximum power (optimal $C p$ ) points versus rotor speed (wind speed as parameters) [4].

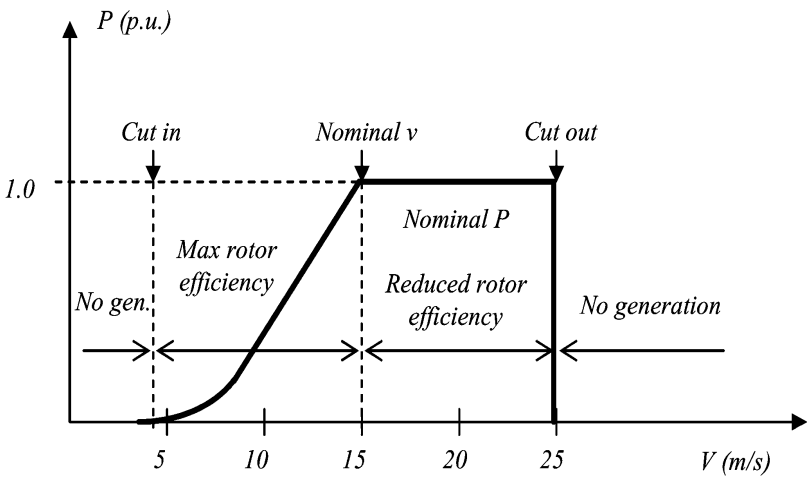

Fig. 12. Output power of a wind turbine as a function of the wind speed

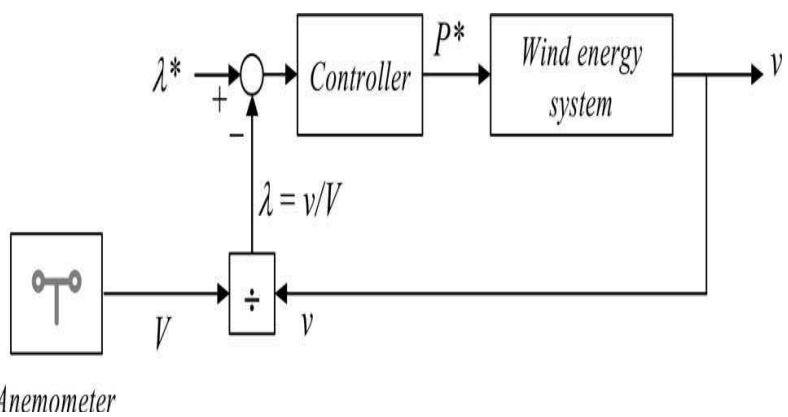

Fig. 13. Block diagram of the TSR control

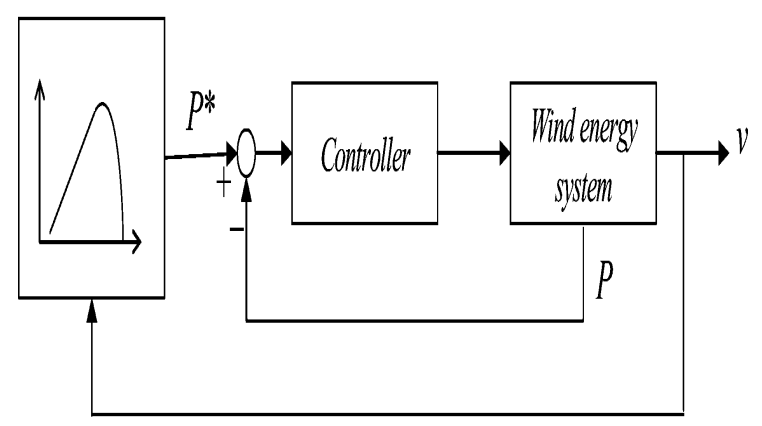

Fig. 14. Block diagram of the PSF control.

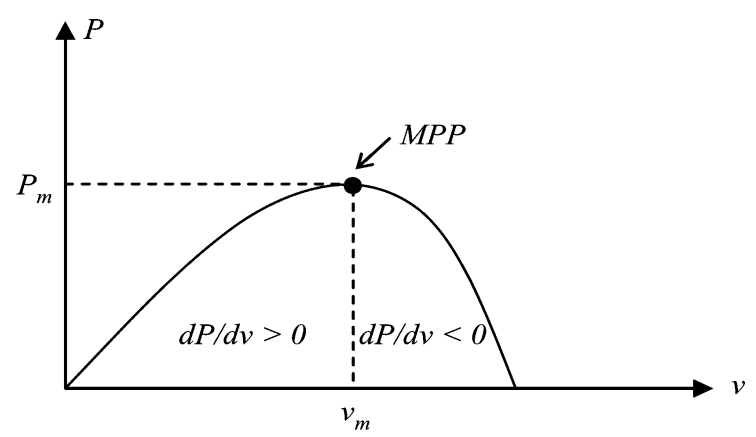

Fig. 15. Block diagram of the HCS control 
3) Hill Climbing Searching (HCS) Control: This control scheme is very similar to MPPT schemes used in photovoltaic systems [1]. When the wind-turbine speed increases, the output power should normally increase as well, otherwise the speed should be decreased (see Fig. 15). However, this method could be ineffective for large wind turbines, since the large turbines are difficult to adjust the speed fast. In practice, MPPT controllers may use combinations of the aforementioned three techniques [14].

\subsection{Possible Wind Farm Configurations}

Large wind farms are being developed in many countries. These wind farms may present a significant power contribution to the grids, and therefore, play an important role on the power quality and the control of power systems. Consequently, high technical demands are expected to be met by these generation units, such as to perform frequency and voltage control, regulation of active and reactive power, quick responses under power system transient and dynamic situations, for example, it may be required to reduce the power from the nominal power to $20 \%$ power within $2 \mathrm{~s}$. The power electronic technology is again an important part in both the system configurations and the control of the wind farms in order to fulfill these demands. Some possible electrical configurations of wind farms are shown in Fig. 16. A wind farm equipped with power electronic converters, as shown in Fig. 16(a), can perform both active and reactive power control and also operate the wind turbines in variable speed to maximize the captured energy as well as reduce the mechanical stress and noise. Such a system is in operation in Denmark as a 160-MW offshore wind power station. Fig. 16(b) shows a wind farm with induction generators where a static synchronous compensator (STATCOM) can be used to provide the reactive power control to meet the system reactive power control requirements. It can help to control the voltage as well as to provide the reactive power demanded by the induction generators in the wind farm, which will be explained in detail in Section III. For long distance power transmission from an offshore wind farm, HVDC may be an interesting option. In an HVDC transmission, the low or medium ac voltage at the wind farm is converted into a high dc voltage on the transmission side and the dc power is transferred to the onshore system where the dc voltage is converted back into ac voltage, as shown in Fig. 16(d). For certain power level, an HVDC transmission system, based on VSC technology, may be used in such a system instead of the conventional thyristors-based HVDC technology. The topology may even be able to vary the speed of the wind turbines in the whole wind farm. Another possible dc transmission system configuration is shown in Fig. 16(c), where each wind turbine has its own power electronic converter, so it is possible to operate each wind turbine at an individual optimal speed. A comparison of the topologies is given in Table I. As it can be seen, the wind farms have interesting features in order to act as a power source to the grid. Some have better abilities than others. The overall considerations will include production, investment, maintenance, and reliability [4]. There are also other possibilities, such as field-excited synchronous machines or PM synchronous generators, that can be sued in the systems, as shown in Fig. 16(c) or (d); in the case of a multiple-pole generator, the gearbox may be removed.

\section{POWER QUALITY IMPROVEMENT WITH POWER ELECTRONIC DEVICES}

Large-scale integration of wind turbines may have significant impacts on the power quality and power system operation. Traditionally, wind turbines are not required to participate in frequency and voltage control. However, in recent years, attention has been increased on wind farm performance in power systems [1]-[2]. Consequently, some grid codes have been redefined to specify the requirements that wind turbines must meet in order to be connected to the grid. Examples of such requirements include the capabilities of contributing to frequency and voltage control by continuously adjusting active power and reactive power supplied to the transmission system, the power regulation rate that a wind farm must provide, flicker, harmonics, etc. Some of the requirements may be dealt with by power electronic technology, for example, reactive power control.

\subsection{Reactive Power and Voltage Control}

The induction-generator-based wind turbines are the consumer of reactive power. To minimize the power losses and increase voltage stability, these wind turbines are compensated to a level depending on the requirements of the power system operators. For wind turbines with PWM converter systems, the reactive power can be controlled by the converter. Thus, these wind turbines have the possibility to control voltage by controlling the generation or consumption of reactive power. The reactive power control can be conducted by following the power system requirement to contribute to the power system voltage control; it can also be performed to minimize the possible voltage fluctuations caused by wind power fluctuations. 

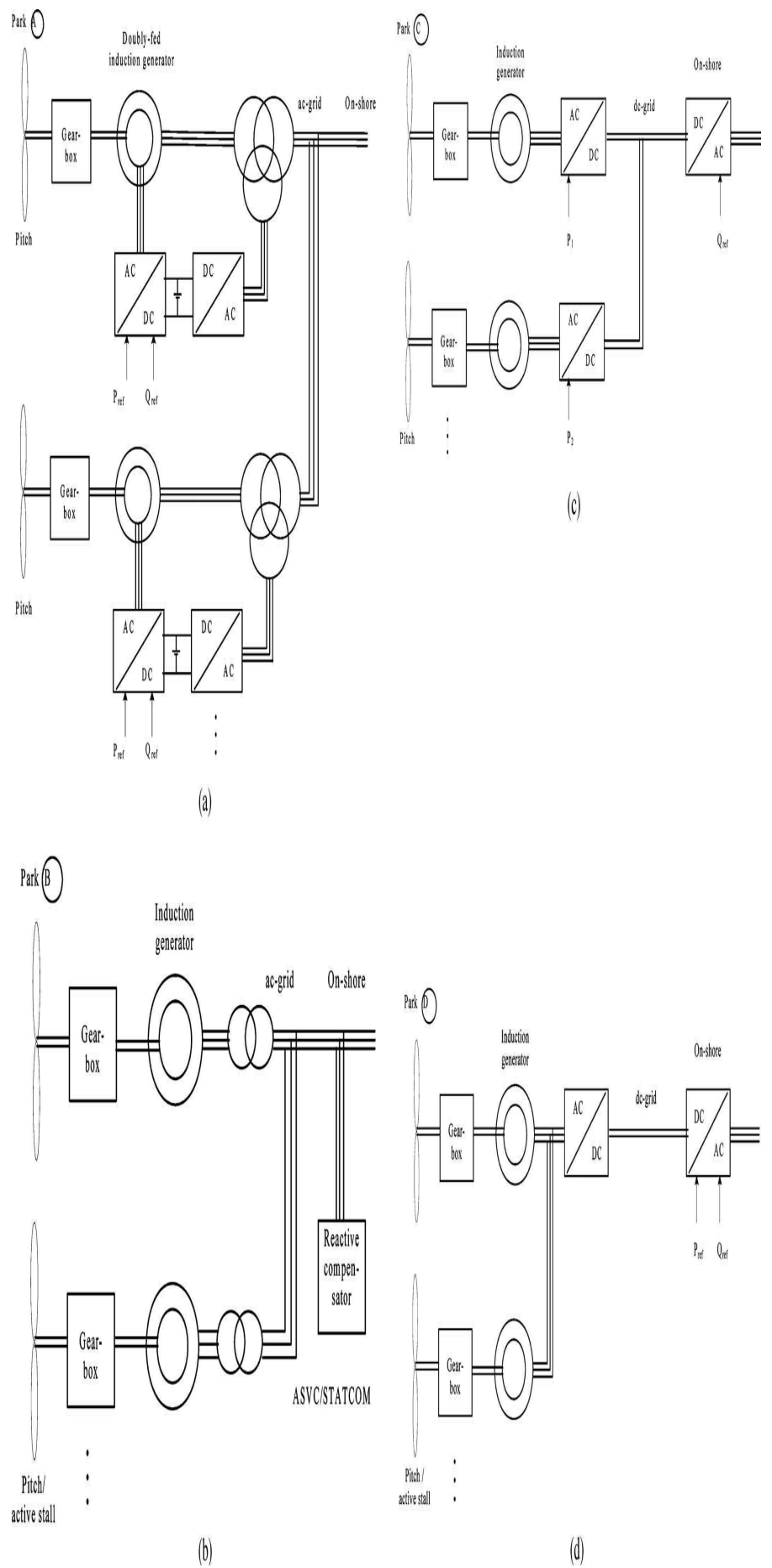

Fig. 16. Wind farm solutions. (a) DFIG system with ac grid (system A). (b) Induction generator with ac grid (system B). (c) Speed-controlled induction generator with common dc bus and control of active and reactive power (system C). (d) Speed-controlled induction generator with common ac grid and dc transmission (system D).
Table 1: Comparison of four wind farm topologies

\begin{tabular}{|c|c|c|c|c|}
\hline Farm monfigurations (Fiv, 10) & A & B & C & D \\
\hline Individual speed coatrol & Yes & Ilo & Yes & No \\
\hline 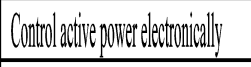 & Yes & $\mathrm{No}$ & Yes & Yes \\
\hline Control reative porrer" & Yes & Centralized & Yes & Yes \\
\hline Shat cinuid(anitre) & Padtly & Pattly & Yes & Yes \\
\hline Shate cimautporier & Contifibute & Contioloute & 10 & Ito \\
\hline Sanadovy-inction & Yess & $\mathrm{Ml}$ & Yes & Yes \\
\hline Solstatereneds & Mo & Yes & 10 & No \\
\hline Rolling cananatyongatit & Yes & Patly & Yes & Yes \\
\hline Inrestment & t & H & $t$ & t \\
\hline Maimtenance & t & H & $t$ & $t$ \\
\hline \multicolumn{5}{|l|}{ 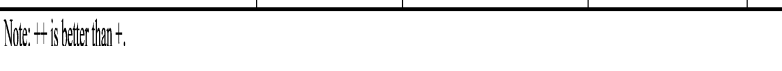 } \\
\hline Grid & $\mathrm{Ig}_{\mathrm{g}}$ & $\mathrm{PCC}$ & $\mathrm{P}_{\mathrm{g}, \mathrm{Q}_{\mathrm{g}}}$ & \\
\hline
\end{tabular}

(a)

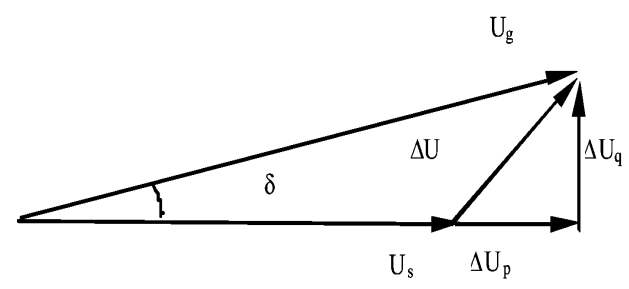

(b)

Fig. 17. Simple power and wind turbine system with an equivalent wind power generator connected to a network. (a) System circuit. (b) Phasor diagram

Approximated as

$$
\Delta U \approx \Delta U p=P g R k+Q g X k / U g
$$

With the grid impedance angle $\psi k$ and the wind turbine power factor angle $\psi$ being defined as

$$
\tan \psi k=X k / R k
$$

$$
\tan \psi=Q g / P g
$$


(3) Can be written as

$$
\left.\Delta U p=P g R k(1+\tan \psi k \tan \psi) \frac{/ U g=P g R k \cos (\psi}{U g \cos \psi k \cos \psi}-\psi k\right)
$$

It can be seen from (5) that when the difference between the grid impedance angle $\psi k$ and the wind turbine power factor angle $\psi$ approaches $90^{\circ}$, the voltage fluctuation is minimized [2]. Equation (5) also indicates that the reactive power may be regulated according to the active power generation to minimize voltage variations and flickers.

The variable-speed wind turbine with power electronic converters is capable of controlling the output active and reactive power. Normally, the output reactive power of the wind turbine is controlled as zero to keep a unity power factor. It is possible to control the output reactive power appropriately with the variation of the output active power so that the voltage changes from the active power flow may be canceled by the reactive power flow. For example, the reactive power may be controlled in proportion to the wind turbine output active power, so that the power factor angle $\psi$ is close to the value of $\psi k+90$. When integrating wind energy into the electrical grid, some situations related to the voltage stability and even the voltage collapse can limit the power injected into the grid. For example, when a voltage dip occurs, wind turbines need reactive power, which can be supplied in some cases by synchronous generators. However, this solution cannot be generalized. Dynamic compensation methods are often used, both inside the wind farm, normally near the PCC, or outside the wind farm, to mitigate these problems [3].

Fig. 17 illustrates an equivalent wind power generation unit, connected to a network with equivalent short-circuit impedance $Z k$. The network voltage at the assumed infinite busbar and the voltage at the point of common coupling (PCC) are $U s$ and $U g$, respectively. Voltage variations caused by fluctuating wind power generation may cause voltage quality problems. Since the phase difference between $U s$ and $U g(\delta)$ is small, the voltage difference $(\Delta U=U g-U s=\Delta U p+j \Delta U Q)$ may be

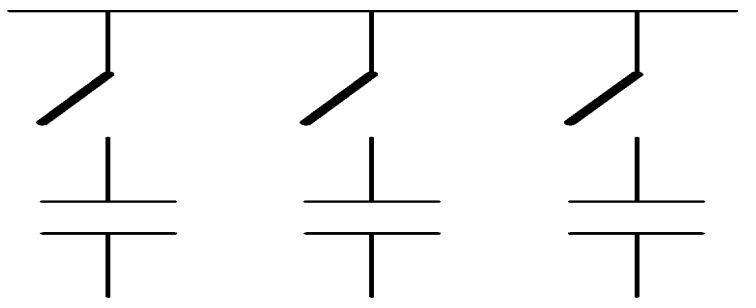

Fig. 18. MSC bank

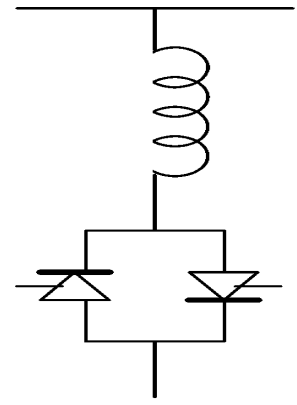

(a)

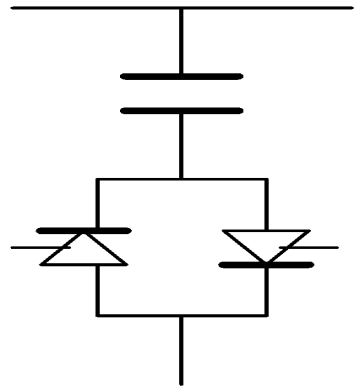

(b)
Fig. 19. SVC basic components. (a) TCR. (b) TSC

\subsection{Compensation inside a Wind Farm}

Voltage stability problems may be derived from the need for reactive power of some wind turbines. This fact becomes more import during a voltage dip since in this case, the problem is to generate enough reactive power for the wind generators. Some existing solutions for transient and steady-state voltage control are as follows.

1) Mechanical Switched Capacitors (MSCs): This solution, depicted in Fig. 18, consists of a bank of shunt capacitors switched mechanically to provide reactive power compensation. The size of each capacitor may be limited in order to avoid large voltage transients. The main problems in the wind farm are that the excessive switching of the capacitor bank provokes failures, applies the inherent voltage steps stress on the wind turbines, and increases the required maintenance of the system.

2) SVCs: These systems use thyristors-controlled components typically thyristors-controlled reactors (TCRs) and TSCs, also together with MSCs to obtain a dynamic controller of reactive power. Normally, SVCs are connected to the collector bus that connects the wind farm to the PCC to provide a desired power factor or voltage level. The SVC can adjust the reactive power, thus to basically solve the steady-state voltage problems. Fig. 19(a) shows a TCR, which is a device consisting of three legs, each of them having an inductor and a static switch. The static switch is formed by two anti parallel connected thyristors. The power is controlled by changing the current flow through the inductor by means of the switch. The $\mathrm{ON}$-state of the thyristors can be adjusted by the firing angle. However, this device generates current harmonics due to the current waveform.

A TSC is shown in Fig. 19(b), which consists of a bank of switched capacitors. Each capacitor has an individual static switch, which is similar to a TCR device, but in this 


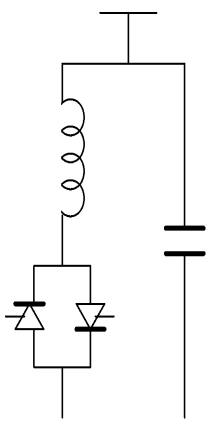

(a)

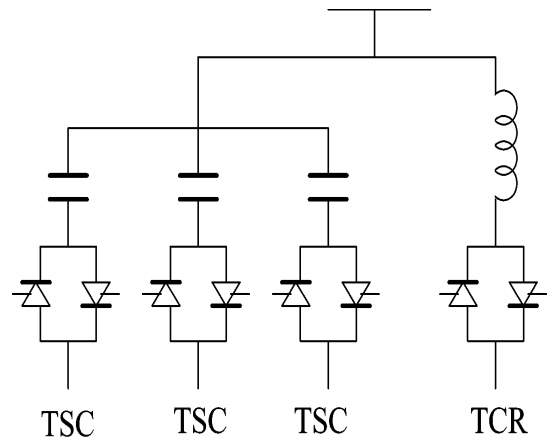

(b)
Fig. 20. Combination of SVCs. (a) TCR with a fixed capacitor. (b) TCR with TSC.

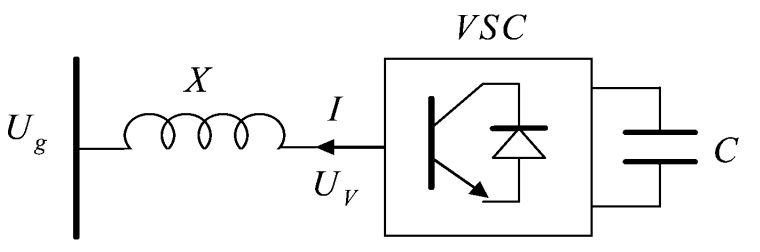

Fig. 21. STATCOM based on VSC connected to the PCC through an inductor case, the switching takes place when the voltage across the thyristors is zero.

Consequently, this device does not produce current harmonics. However, due to the use of switching capacitors, TSC may produce voltage transients. The combinations between these components can provide good performances of compensation. For instance, TCR can be combined with fixed capacitors or with TSC, as shown in Fig. 20. In the first case, a TCR is used in combination with a fixed capacitor bank. This solution is often used for sub transmission and distribution. The current harmonics may be eliminated by tuning the fixed capacitors as passive filters. The second case combines TCR and TSC in one compensator system. Hence, a continuously variable reactive power is obtained across the entire control range plus full control of both inductive and capacitive parts of the compensator.

3) STATCOM: This system, also named SVC Light by ABB, is based on a VSC, which is used to generate reactive power. The VSC uses power electronic devices such as IGBTs, IGCTs, or gate turn-OFF thyristors (GTOs), and they can also be configured as a multilevel bidirectional converter. As shown in Fig. 21, the VSC is connected to the grid to inject or absorb reactive power through an inductor $X$. This system is suitable to mitigate both steady-state and transient events. Compared with SVCs, STATCOMs provide faster response, less disturbances, and better performance at reduced voltage levels. From Fig. 21, if the power angle remains zero $(\delta=0)$, the active and reactive power injected to the grid by the STATCOM can be expressed as

$$
\begin{gathered}
P=U g U V / X \sin \delta=0 \\
Q=U g U V / X \cos \delta-U 2 g / X=U g / X(U V-U g)
\end{gathered}
$$

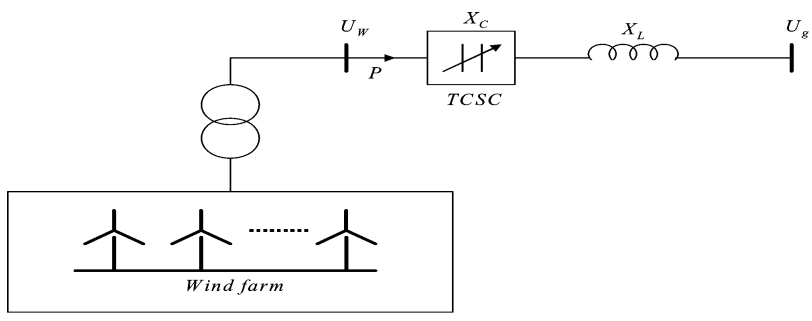

(a)

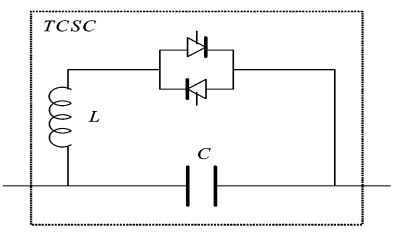

(b)

Fig. 22. TCSC. (a) Wind farm connection. (b) Detail of the TCSC

Consequently, the VSC acts as a reactive power generator $(Q$ $>0$, capacitive behavior) if $U V>U g$, and as a reactive power absorber $(Q<0$, inductive behavior) if $U V<U g$. In practice, a small phase shift is used to compensate the VSC losses. The reactive power injected to the grid can be controlled faster than by using previous systems. The response time is limited by the switching frequency and the size of the inductor.

\subsection{Compensation outside a Wind Farm}

In order to send the active power generated by a wind farm into the grid, the power transmission control has to be taking into account. Power oscillations and voltage collapses should be avoided. Fig. 22 shows a possible solution to avoid these drawbacks, which uses a thyristors-controlled series compensation (TCSC) outside the wind farm. The TCSC changes the equivalent capacitor value by switching the parallel-connected inductor [2]. This way, a variable capacitor can be obtained and can be adjusted to increase the dynamic stability of power transmission, improve the voltage regulation and the reactive power balance, and control the power flow of the grid lines. From Fig. 22(a), it can be seen that the active power transmitted from the wind farm to the grid can be expressed as follows:

$$
P=U g U W / X L-X C \sin \delta
$$

Where $X L$ is the reactance of the power line, $X C$ is the admittance of the TCSC, $U g$ is the voltage of the grid, $U W$ is the voltage of the wind farm, and $\delta$ is the angle between $U g$ and $U W$. From this equation, the relationship between $P$ and $\delta$ can be plotted, as shown in Fig. 23. It can be observed that the 
reactance value limits the maximum power to be transmitted, and enforces a larger power angle that can lead to instabilities and oscillations. However, if a TCSC is added, both the total equivalent impedance of the power line and the power angle can be reduced, thus improving the steady-state and the transient system behavior. This system may be useful for wind farms located far away from the PCC, such as offshore wind farms.

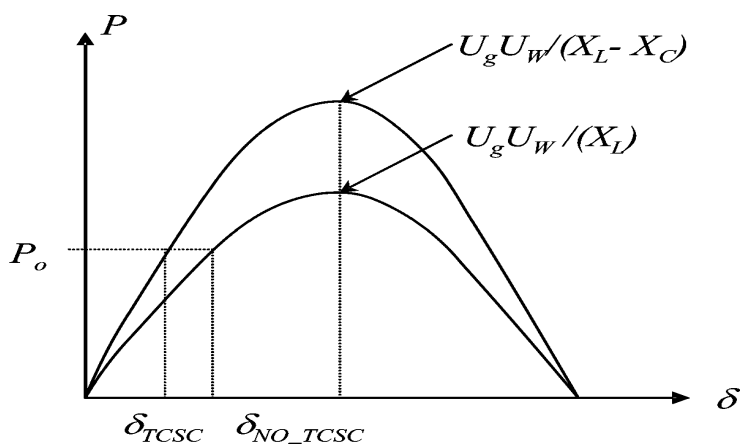

Fig. 23. Active power injected from the wind park to the grid

\subsection{Flickers}

Fluctuations in the system voltage (in terms of rms value) may cause perceptible light flicker depending on the magnitude and frequency of the fluctuation. Rapid variations in the power output from a wind turbine, such as generator switching and capacitor switching, can also result in variations in the rms value of the voltage. At certain rate and magnitude, the variations cause flickering of the electric light. Thus, this type of disturbance is called voltage flicker. In order to prevent flicker emission from impairing the voltage quality, the operation of the generation units should not cause excessive voltage flicker. Flicker evaluation based on IEC 61000-3-7 gives guidelines for emission limits of fluctuating loads in medium-voltage and high-voltage networks. Determination of flicker emission can be done on the basis of measurement. In fact, the flicker meter specified in IEC 61000-4-15 can be used to measure flicker directly. The flicker emissions may also be estimated with the coefficient and factors $c f(\Psi k, v a)$ and $k f$ $(\Psi k$ ) obtained from the measurements, which are usually provided by wind turbine manufacturers [2]. Voltage variation and flicker emission of grid-connected wind turbines are related to many factors, including

1) Mean wind speed $v$;

2) Turbulence intensity In;

3) Short-circuit capacity ratio $\mathrm{SCR}=S k / S n$, where $S k$ is the short-circuit capacity of the grid where the wind turbinesare connected and $S n$ is the rated power of the windturbine. A simulation study has been carried out to investigate the flicker minimization by using reactive power compensation. The results, as shown in Fig. 24, indicate that the flicker level is significantly reduced if the angle difference $(\psi-\psi k)$ is regulated to be 90 by controlling the reactive power flow. The wind turbine output reactive power may be controlled to vary with the output active power so that the difference between the grid impedance angle $\psi k$ and the power factor angle $\psi$ may approach $90^{\circ}$, which leads to reduced flicker levels. The flicker emissions of variable-speed wind turbines with DFIGs during continuous operation are shown in Fig. 25 for the cases with output reactive power control, i.e., the angle difference $\psi$ - $\psi k$ being regulated to be $90^{\circ}$, and the cases of normal operation. The comparison is done with different parameters, such as mean wind speed, turbulence intensity, and shortcircuit capacity ratio. The relationships between the short-term flicker severity Pst and the concerned parameters in the two cases have the similar pattern. However, compared with the case of normal operation, when the angle difference $\psi-\psi k$ is kept to be $90^{\circ}$ by controlling the reactive power, the flicker level is significantly reduced. It can be concluded that regulating the angle difference $\psi-\psi k$ by controlling the wind turbine output reactive power is an effective way for flicker mitigation regardless of mean wind speed, turbulence intensity, and short-circuit capacity ratio. Similarly, a wind turbine system with the full rated power electronic system can perform such control as well. It is clear that the variable-speed wind turbines with power electronic interface are capable of controlling the output active and reactive power independently, and hence, power quality can be improved.

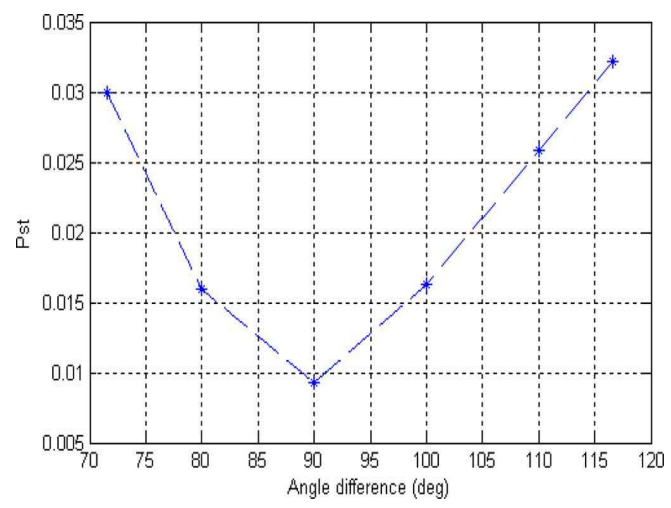

Fig. 24. Short-term flicker severity $P s t$ versus angle difference $\psi-\psi k\left(v=9 \mathrm{~m} / \mathrm{s}, \operatorname{In}=0.1, \mathrm{SCR}=20 \psi k=63.4^{\circ}\right)[25]$.

\section{SYSTEMS DYNAMIC STABILITY IMPROVEMENT WITH POWER ELECTRONICS}

An important issue of integrating large-scale wind farms is the impact of the wind power technologies on the stability and transient behavior of the power systems [2]-[3]. The problem of network stability is often associated with different types of faults in the network, such as tripping of transmission lines (e.g., overload), loss of production capacity, and short circuits. Short circuits have a variety of forms, and most of them are cleared with relay protection systems either by disconnection 
and fast reclosure or by disconnection of the equipment in question after a few hundred milliseconds.

\subsection{Fault Ride-Through of Induction Generators}

During a short-circuit fault in a power system where the wind turbines are connected, the short-circuit current may result in with relay protection systems either by disconnection and fast reclosure or by disconnection of the equipment in question after a few hundred milliseconds.

\subsubsection{Fault Ride-Through of Induction Generators}

During a short-circuit fault in a power system where the wind turbines are connected, the short-circuit current may result in a voltage drop at the wind generator terminal. Due to the voltage dip, the output electrical power and the electromagnetic torque of the wind turbine are significantly reduced, while the mechanical torque may be still applied on the wind turbine. Consequently, the turbine and generator will be accelerated due to the torque unbalance.

After the clearance of the fault, the voltage of the power system tends to recover. However, reactive power is required to recover the air gap flux of the induction generators. This could cause an inrush current to be drawn by the wind generators from the power system, which, in turn, causes a voltage drop on the lines between the power system and the wind turbines. The voltage drop could prevent the machine terminal voltage returning quickly to the normal value. If the voltage could be recovered and the generator speed is not too high, the electromagnetic torque could be restored. Then, the reestablished electromagnetic torque will act on the rotor in the opposite direction to the mechanical torque from the wind turbine. If the electromagnetic torque is big enough, the rotor speed can be slowed down and the wind turbine may restore its normal operation eventually [9]. On the contrary, if the voltage is not able to be recovered back to around the normal value or the generator speed is too high, there may be no sufficient electromagnetic torque to balance the mechanical torque. Hence, the machine would continue to accelerate and the increase in machine speed will lead to an increased reactive power consumption, which can be seen from the machine characteristics. Then, the voltage may decrease further and if the generator will not return to its normal speed, it has to be tripped out by over speed protection devices. When this happens, the wind turbine is disconnected and failed to ride through the fault. Wind turbine disconnection caused by dipped voltage and inrush current should be avoided because losing a significant part of the power generation capacity could threaten the security of the power system. Many power systems have made grid codes to require that the wind turbines be connected in the system during a power system fault, in order to support the system recovery from a fault and prevent power system from collapse caused by further losing generation capacity. This becomes more significant as wind power penetration level increases. The methods to achieve the target may be different. However, the main tasks are voltage recovery and speed control. Only if the voltage level is restored, the magnetic field of the generators can be reestablished, and then, electromagnetic torque can be restored. Therefore, a quick recovery of voltage and reestablishment of the electromagnetic torque are crucial.

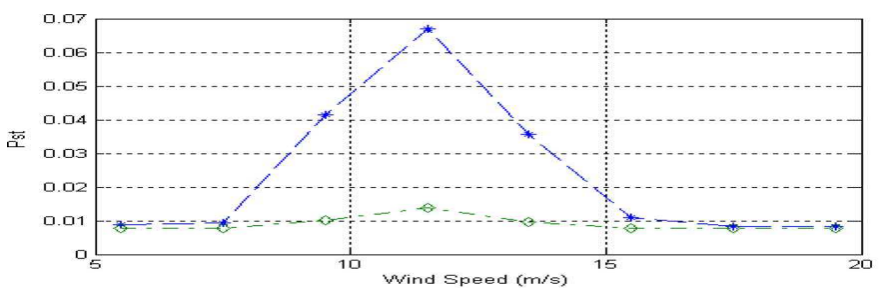

(a)

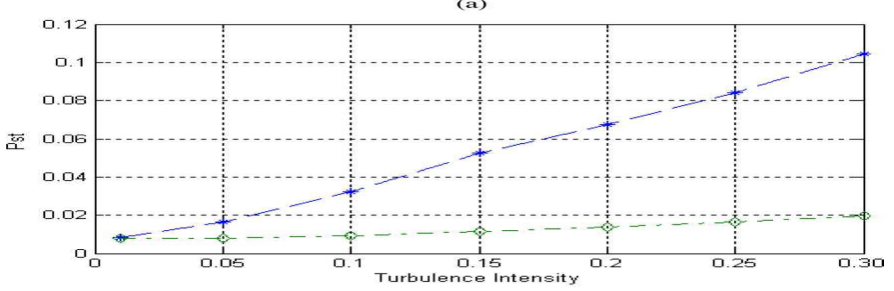

(b)

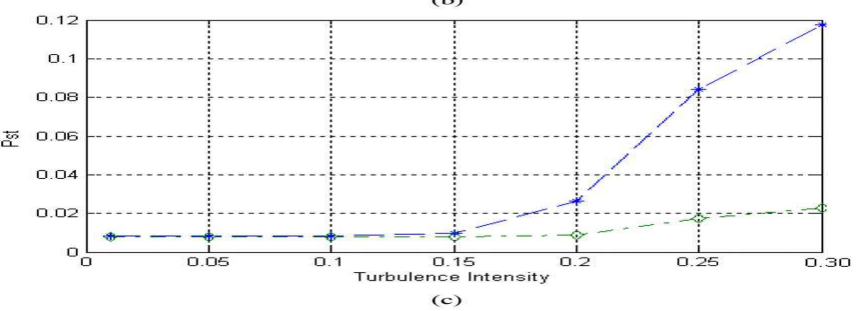

(c)

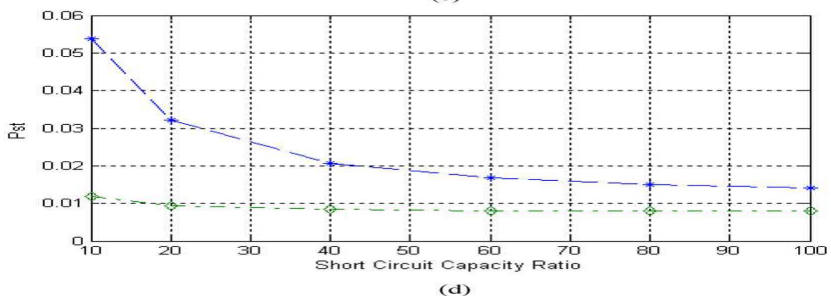

(d)

Fig. 25. Reactive power compensation effects on short-term flicker severity Pst normal operation (asterisk) with output reactive power control (diamond) [25]. (a) Pst versus mean wind speed $\left(I n=0.1, \mathrm{SCR}=20, \psi k=63.4349^{\circ}\right)$. (b) Pst versus turbulence intensity in low wind speeds $(v=9 \mathrm{~m} / \mathrm{s}, \mathrm{SCR}=20$, $\psi k=63.4349^{\circ}$ ). (c) $P s t$ versus turbulence intensity in high wind speeds $\left(v=18 \mathrm{~m} / \mathrm{s}, \mathrm{SCR}=20, \psi k=63.4349^{\circ}\right)$. (d) $P s t$ versus short-circuit capacity ratio $(v=9 \mathrm{~m} / \mathrm{s}, I n=0.1, \psi k=$ $63.4349 \circ)$.

The over speed of a generator may also be limited by controlling the input mechanical torque. Turbines equipped with a pitching system have the advantage of actively pitching down the input mechanical torque, which will effectively limit the acceleration of the generator system. An example system is shown in Fig. 26, where two generators (one cage rotor and 
one wound rotor with rotor resistance and pitch control) are connected in parallel [3] and a load at bus 2 is supplied by the wind power generators and by the external power system represented by a constant voltage source connected in series with its Thevenin's equivalent impedance. A STATCOM is connected to bus 2 as well. During the rated operation, the wind turbine provides a part of the load at bus 2 in the system. The capacitors at the wind turbine terminal supply the reactive power required by the generator and the STATCOM may also supply a part of reactive power.

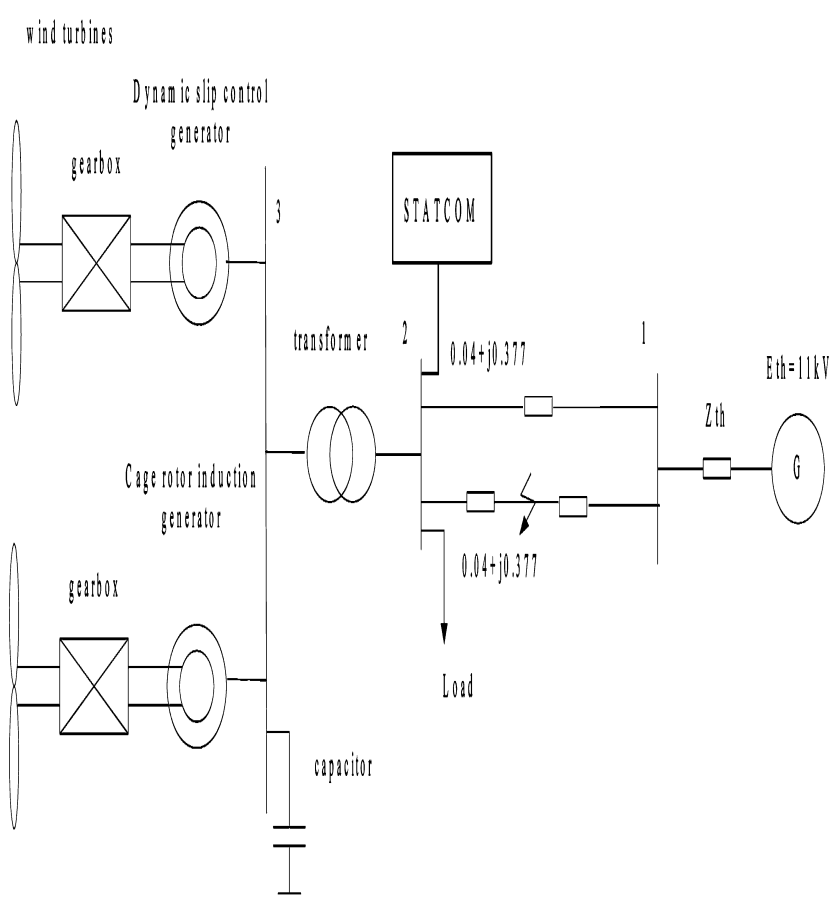

Fig. 26. Block diagram of a wind turbine connected to a grid [7].

Fig. 27 shows the simulation results where the STATCOM is not in operation, but the extended rotor resistance control and turbine pitch control are applied on the wound rotor induction generator. It can be seen that the terminal voltage cannot restore and the cage induction generator continues accelerating and loses the stability. Although the acceleration of the wound rotor induction generator has been limited by the extended rotor resistance control and the pitch control for a certain period, the speed of the generator will rise again after the controls have been removed. The reason is that the low voltage cannot be restored since the parallel cage induction generator loses the stability.

However, part of the system may be restored if the unstable cage rotor induction generator is disconnected from the system.
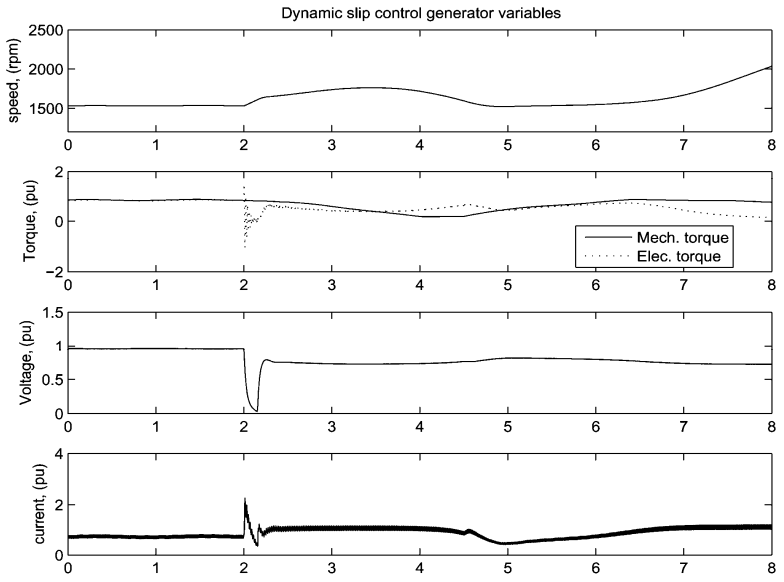

(a)
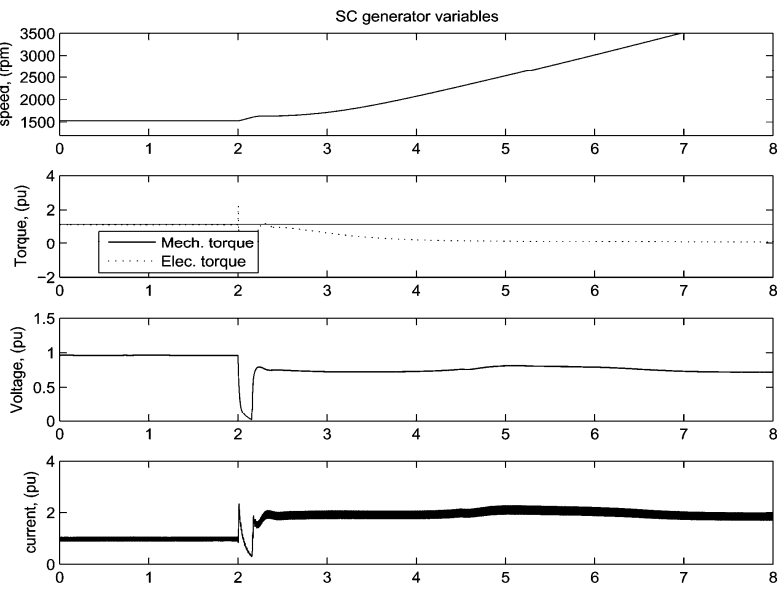

(b)
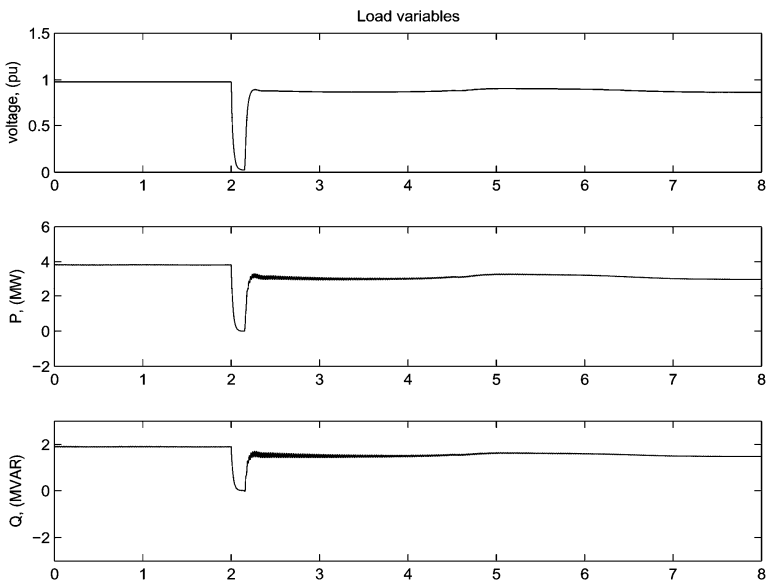

(c)

Fig. 27. Simulation results with extended rotor resistance and pitch control and without STATCOM. (a) Dynamic slip rotor resistance control generator variables. (b) Cage induction generator variables. (c) Load voltage, power, and reactive power. 

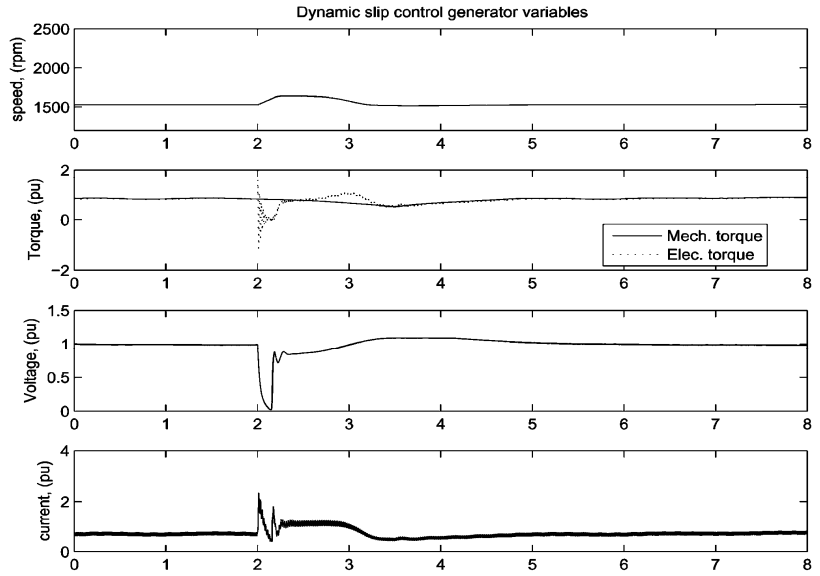

(a)
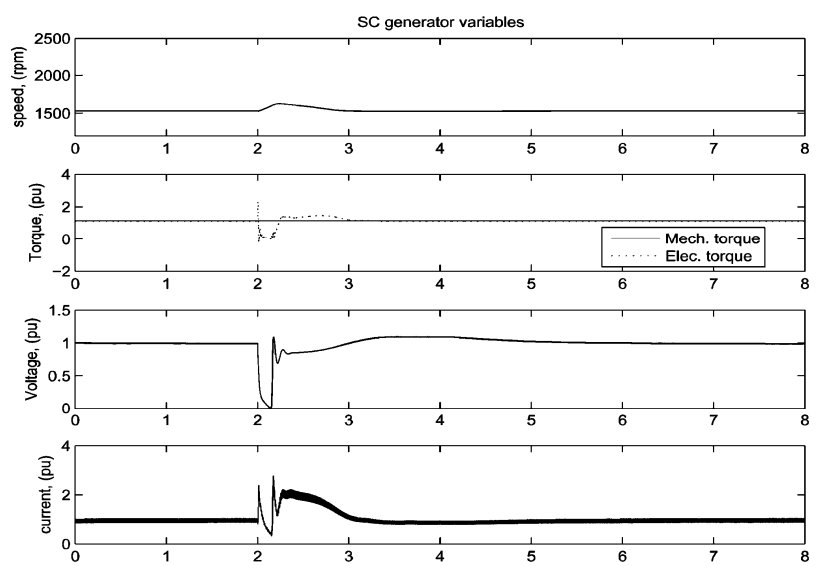

(b)
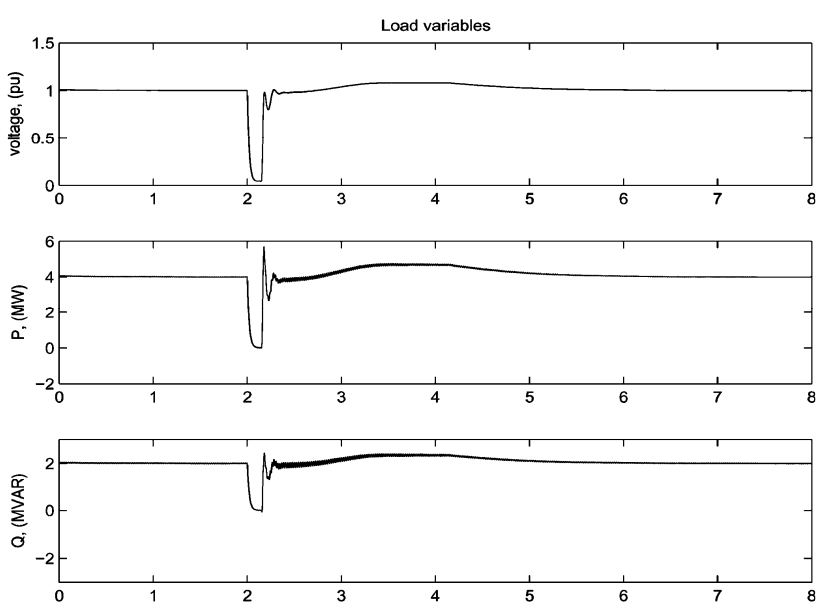

(c)

Fig. 28. Simulation results with STATCOM in operation, and sufficient rotor resistance and pitch control. (a) Dynamic slip rotor resistance control generator variables. (b) Cage induction generator variables. (c) Load voltage, power, and reactive power.
Fig. 28 shows the results of a successfully restoring stability case, where the STATCOM is in the operation and the rotor resistance and pitch control are also sufficiently regulated so that the system restores normal operation.

The example has been shown as an important function of STATCOMs. It is also shown that the appropriate combination of various control approaches is an effective way to improve the stability.

\subsubsection{Fault Ride-Through of DFIG with a Crowbar}

As discussed previously, a voltage drop will spur an electromagnetic torque reduction that leads to the acceleration of the rotor. The grid voltage decreases rapidly to a low level and will cause high current transients in the generator stator and also in the rotor, due to the magnetic coupling between the stator and rotor [7]. The high current may damage the power electronics converter connected with the rotor winding of DFIGs. Therefore, protection measures are required for DFIG wind turbines during voltage dips. A reduction in mechanical torque is desired in order to avoid over speed. A pitch regulation, as explained before, can be used. To avoid damages in power electronics, the most common option is to block the rotor-side converter and short circuit the rotor winding by means of a so-called crowbar[8], [.9].

A crowbar is connected between the rotor of the DFIG and the rotor-side converter. The crowbar circuit may have various topologies, for example, Fig. 29 shows a crowbar consisting of a diode bridge that rectifies the rotor phase currents and a single thyristors in series with a resistor Rcrow. The thyristors is turned on when the dc-link voltage reaches its limit value or the rotor current reaches its limit value. Simultaneously, the rotor of the DFIG is disconnected from the rotor-side power electronic converter and connected to the crowbar. The rotor remains connected to the crowbar until the main circuit breaker disconnects the stator from the network. When the grid fault is cleared, the rotor-side converter is restarted, and after synchronization, the stator of the DFIG is connected back to the network. Rotor over current protection described before is called a passive crowbar.

The same circuit topology, as shown in Fig. 29, may be changed to an active crowbar [9] by replacing the thyristors with a fully controllable one by means of a controllable semiconductor switch, such as an IGBT. This type of crowbar may be able to cut the short-circuit rotor current at anytime. If either the rotor current or the dc-link voltage levels exceed the limits, the IGBTs of the rotor-side converter are blocked and the active crowbar is turned on. The crowbar resistor voltage and dc-link voltage are monitored during the operation of the Crow bar. When both of these voltages are low enough, the crowbar may be turned off. After a short delay for the decay of the rotor currents, the rotor-side converter may be restarted and the reactive power may be produced to support the grid. 
During normal operation, active and reactive power is controllable and the machine is magnetized by the rotor. However, while the rotor-side converter is disabled and bypassed, the controllability of active and reactive power gets lost and the magnetization is carried out by the stator, as in an SCIG. The selection of the Rcrow value could affect the system performance, such as reactive power controllability [40]. Doubly fed generators with rotor current control are prone to oscillations when reactive power is fed to the grid. During a voltage dip, the stability limit is further reduced. However, the generators with direct torque control (DTC) instead of vector current control seems to be reasonably stable, which could allow the rated reactive current production under low grid voltages, though voltage dips with highly unsymmetrical voltages are still difficult for DFIGs [1].

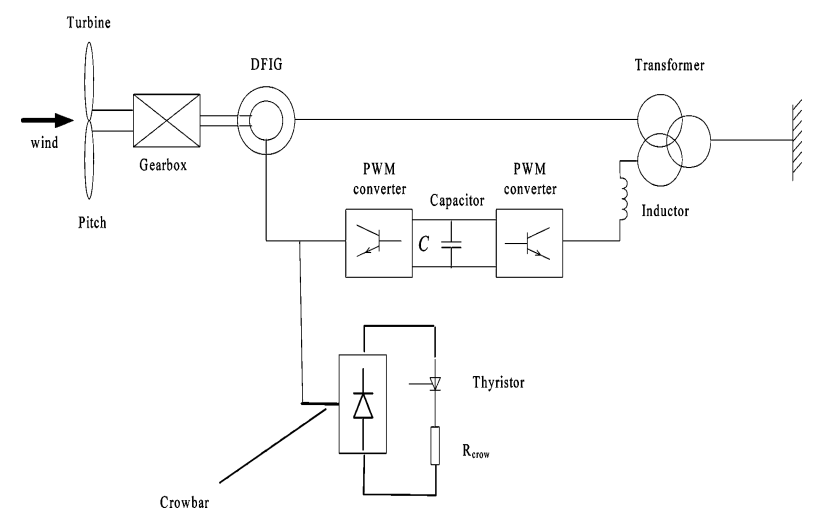

Fig. 29. Crowbar connected between the rotor of the DFIG and rotor-side converter.

\section{CONCLUSIONS AND FUTURE TRENDS}

This paper has reviewed the power electronic applications for wind energy systems. Various wind turbine systems with different generators and power electronic converters are described. Different types of wind turbine systems have quite different performances and controllability. The electrical topologies of wind Farms with different wind turbines are briefed. It has been shown that the wind farms consisting of different turbines may need different configurations for the best use of the technical merits.

Furthermore, the possible methods of improving wind turbine performance in power systems to meet the main grid connection requirements have been discussed. The wind turbine size is still increasing. Both onshore and offshore wind farms are quickly developing in a global scale.

While the wind turbine market continues to be dominated by conventional gear-driven wind turbine systems, the direct drive or one-stage gear, so-called multibrid-type wind system, is attracting attention. Variable-speed operation has many advantages. On the one hand, the DFIG dominates the current market for variable-speed gear-driven wind turbine systems, largely due to the fact that only the power generated in the generator rotor has to be fed through a power electronic converter system $(25 \%-30 \%)$.On the other hand, variablespeed wind turbines with a full-scale power converter may be more effective and less complicated to deal with grid-related problems, including the possibility for active grid support, and the potential to operate wind turbines and wind farms as power plants. Therefore, variable speed wind turbine concepts with a full-scale power converter would become more attractive.

Many power electronics configurations for wind turbine systems have been actively researched, mainly the VSCs, including Multi converter configurations, are used. Compared with geared drive wind generator systems, the main advantages of direct drive wind generator systems are higher overall efficiency, reliability, and availability due to omitting the gearbox.PM machines are more attractive and superior with higher efficiency and energy yield, higher reliability, and power-to-weight ratio compared with electricity-excited machines [2].With synchronous generators, diode rectifiers may be used as the machine-side converters [4]. Furthermore, studies on the use of current-source converters for grid converters are reported [3], [4]. Considering the performance of PMs is improving and their cost is decreasing over the recent years, combined with the fact that the cost of power electronics is decreasing, variable-speed direct drive PM machines with a full-scale power converter have become more attractive for offshore wind powers.

Although the market share in the fixed-speed wind turbine concept has decreased, the market interest in SCIG-based wind turbines may increase. VSC-HVDC-based wind farms consisting of SCIG are robust to grid faults. Because VSCHVDC can enhance the ability to prevent power system faults, consequently, the generators that are sensitive to power system faults such as SCIG can be used without the problem of ridethrough power system faults. With the increasing levels of wind turbine penetration in modern power systems, grid connection issues have posed several new challenges to wind turbine design and development. Coping with grid connection demands is becoming a major issue in the wind turbine industry. Recently, grid connection requirements are becoming more strict. One of the requirements is that in case of a major grid disturbance, wind turbines not only have to remain connected, but should also play an assisting role. In future, the percentage of wind energy on many grids is expected to be a significant part, thus making wind turbines as key grid players. Therefore, these machines will require a built-in capacity to behave like power plants. Power electronic technologies, as the interfaces for wind turbines, also the interfaces for some energy storage systems and as flexible ac transmission systems (FACTs) devices, such as STATCOM, 
will play a significant role in developing new state-of-the-art solutions for the future

\section{REFERENCES}

[1]. A. D. Hansen, C. Jauch, P. Soerensen, F. Iov, and F. Blaabjerg. (2003). Dynamic wind turbine models in power system simulation tool DigSilent. Report Risoe-R-1400 (EN) [Online]. $\quad$ pp. 1-80. Available: http://www.digsilent.de/Software/Application_Examples/ris-r 1400.pdf

[2]. Z. Chen, Y. Hu, and F. Blaabjerg, "Stability improvement of induction generator-based wind turbine systems," IET Proc. Renewable Power Generation, vol. 1, no. 1, pp. 81-93, Mar. 2007.

[3]. A. B. Raju, K. Chatterje, and B. G. Fernandes, "A simple maximum point tracker for grid connected variable speed wind energy conversion system with reduced switch count power converters," in Proc. IEEE PESC 2003, vol. 2, pp. 748753.

[4]. Power Quality Requirements for Wind Whines, IEC Standard 61400-21, 2001.

[5]. S. K. Salman and A. L. J. Teo, "Windmill modelling consideration and factors influencing the stability of a gridconnected wind power-based embedded generator," IEEE Trans. Power Syst., vol. 18, no. 2, pp. 793-802, May 2003.

[6]. Renewable energy sources by sukatme.

[7]. Non - conventional energy sources by G.D.RAI.

[8]. Handbook of renewable energy technology by R.BANSAL AND A.ZOBAA.

[9]. Power electronics by Mohammad .H. RASHID. 